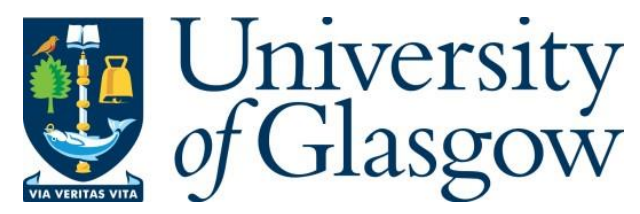

Nati, J. J.H., Lindström, J., Yeomans, W. and Killen, S. (2018) Physiological and behavioural responses to hypoxia in an invasive freshwater fish species and a native competitor. Ecology of Freshwater Fish, 27(3), pp. 813-821.

There may be differences between this version and the published version. You are advised to consult the publisher's version if you wish to cite from it.

This is the peer reviewed version of the following article Nati, J. J.H., Lindström, J., Yeomans, W. and Killen, S. (2018) Physiological and behavioural responses to hypoxia in an invasive freshwater fish species and a native competitor. Ecology of Freshwater Fish, 27(3), pp. 813-821, which has been published in final form at http://dx.doi.org/10.1111/eff.12394. This article may be used for non-commercial purposes in accordance with Wiley Terms and Conditions for Self-Archiving.

http://eprints.gla.ac.uk/154989/

Deposited on: 10 January 2018

Enlighten - Research publications by members of the University of Glasgow http://eprints.gla.ac.uk 


\section{Physiological and behavioural responses to hypoxia in an invasive freshwater fish}

species and a native competitor

4 Julie J.H. Nati*1 ${ }^{1}$, Jan Lindström ${ }^{1}$, William Yeomans ${ }^{1,2}$ and Shaun S. Killen ${ }^{1}$

$5{ }^{1}$ Institute of Biodiversity, Animal Health and Comparative Medicine, University of Glasgow,

6 Graham Kerr Building, Glasgow G12 8QQ, UK

$7{ }^{2}$ Clyde River Foundation, Graham Kerr Building, University of Glasgow, Glasgow G12 8QQ,

$8 \quad \mathrm{UK}$

$9 *$ Corresponding author: julienati3@gmail.com

10 Running title: Hypoxia tolerance between an invasive and native freshwater fish species

\section{Abstract}

The spread of invasive species is one of the major environmental concerns which can have negative effects on biodiversity. While several life history traits have been identified as being important for increasing the invasiveness of introduced species, the physiological factors that allow certain species to become successful invaders remain poorly understood. It has been speculated that good invaders are thriving in disturbed environments. In unfavourable conditions, as during hypoxic events, invasive species might be better adapted in their physiological and behavioural responses towards this stressor. We compared physiological and behavioural traits between two freshwater fish species: the European bullhead (Cottus gobio), an invasive fish species in Scotland, and its native competitor the stone loach (Barbatula barbatula) over different dissolved oxygen concentrations (DO). Contrary to expectations, bullhead displayed a reduced hypoxia tolerance as compared to stone loach, indicated by a higher threshold $\left(\mathrm{P}_{\text {crit }}\right)$ for the maintenance of standard metabolism. Avoidance behaviour during progressive hypoxia was similar between bullhead and stone loach. When given a choice between an open normoxic zone and a shelter located in hypoxia, both species spent most of their time hiding under the shelter in hypoxic conditions (bullhead: 100\%; stone loach: 93.93-99.73\%), although stone loach showed brief excursions into normoxic conditions under $25 \%$ DO level. These results suggest that stone loach might be more resistant to 
hypoxia as compared to bullhead, and thus that increased hypoxia tolerance is likely not a trait by which bullhead have been able to expand their range within the UK.

Keywords: hypoxia tolerance, invasive species, bullhead, behavioural response, stone loach, $\mathrm{P}_{\text {crit }}$

\section{Introduction}

Over the last 30 years the introduction events of non-native species into novel ecosystems has more than doubled (Williamson \& Fitter, 1996; Gozlan, 2008) and continues to increase due to human activities (Sala et al., 2000). Fishes are one of the most introduced taxa worldwide with approximately 624 species being established in non-native habitats (Gozlan, 2008). The effects of introduced species on freshwater ecosystems are numerous, and include habitat modification (Moyle, 1986; Kitchell et al., 1997), loss of biodiversity due to predation and competition (Kitchell et al., 1997; Blanchet et al., 2007), introduction of diseases (Gozlan et al., 2005; Gozlan et al., 2006) and hybridisation (Costedoat et al., 2004; D’Amato et al., 2007). Introduced species are considered invasive when they persist and consistently harm the native ecosystem. Some invasive species establish localised populations, while others spread and extent their distribution range. Certain environmental conditions can favour the spread of invasive species.

Hypoxic events can cause significant disturbance to aquatic community structure and provide opportunities for invasive species to colonise novel ecosystems (Jewett et al., 2005). This is especially likely if a potential invader has the physiological and behavioural abilities to tolerate restricted access to environmental oxygen. Unfortunately, the frequency and severity of hypoxic events in aquatic ecosystems are increasing worldwide (Diaz, 2001; Diaz \& Rosenberg, 2008). In lentic and lotic freshwater systems, hypoxia is caused by a number of factors including eutrophication, algal respiration, inflow of industrial waste, reduced mixing due to depth or wind conditions, thermal variation and ice cover (Poff et al., 2002; Ficke et al., 2007). Many temperate freshwater fishes are negatively affected by hypoxia (Graham \& Harrod, 2009) indicated as reduced growth, limited swimming performance and reproductive output and an increase in physiological stress (Herbert \& Steffensen, 2005; Domenici et al., 2007; Richards et al., 2009). 
Invasion success in non-native species is thought to be facilitated by a wider tolerance range for fluctuating environmental conditions, such as oxygen availability (Kolar \& Lodge, 2002; Jewett et al., 2005; Lenz et al., 2011). Despite the generally negative effects of hypoxia on fishes, species vary in their abilities to cope with reduced oxygen availability. Species can differ in their oxygen demands for maintenance metabolism and have different morphological, physiological and behavioural adaptations for reducing activity-related oxygen requirements or for increasing the oxygen extraction from the environment (Schurmann \& Steffensen, 1997; Herbert \& Steffensen, 2005; Landman et al., 2005). Pelagic migratory fishes tend to increase activity during severe hypoxic events to escape and find more favourable habitats (Domenici et al., 2000; Herbert \& Steffensen, 2005; Brady et al., 2009), whereas sedentary benthic fish often reduce activity as means to reduce energy expenditure and oxygen demand (Chapman \& McKenzie, 2009). The particular behavioural strategy for dealing with hypoxia may also depend on the prevailing level of predation risk, including shelter availability, because any increase in activity may increase the chance of encountering predators (Killen et al., 2012b). From a physiological standpoint, standard metabolic rate (SMR; the minimum energy required to sustain life) remains stable under moderate hypoxia (50\% air saturation). With decreasing dissolved oxygen (DO), however, fish will reach a threshold referred to as the critical oxygen partial pressure $\left(\mathrm{P}_{\text {crit }}\right)$ at which point oxygen availability is limiting and insufficient to sustain SMR. The measurement of $\mathrm{P}_{\text {crit }}$ is often used as a benchmark for hypoxia tolerance in species, with hypoxia-tolerant species having lower $\mathrm{P}_{\text {crit }}$ values compared to less tolerant species (Mandic et al., 2009a, b; SpeersRoesch et al., 2013).

Under changing environmental conditions, hypoxia-tolerant species may be able to colonise novel habitats where the conditions have become unsuitable for native competitors or predators. For fishes, comparative studies of hypoxia tolerance between native and non-native freshwater species are scarce (Morosawa, 2011; Elshout et al., 2013). This is surprising, given the abundance of invasive fish species and the pervasiveness of hypoxia in aquatic environments. In this study, we investigated metabolic and behavioural responses to progressive hypoxia in bullhead (Cottus gobio Linnaeus 1758) and stone loach (Barbatula barbatula Linnaeus 1758). Stone loach is native to Scottish freshwater river ecosystems whereas bullhead has been introduced in stony streams and rivers with low to moderate flow regimes and is considered invasive (Maitland \& Campbell, 1992). Both species are benthic 
potentially compete for resources (e.g. food and shelter). Like most temperate freshwater systems, Scottish waterways experience seasonal low dissolved oxygen events associated with flow, nutrient runoff and temperature (Anderson et al., 2010), in particular during the summer in low flow and side-pool sections of riverine systems. The invasion success of bullhead in their non-native range may be linked to increased hypoxia tolerance as compared to native stone loach, especially given that they belong to the order of Cottidae (sculpins), which have been shown in marine systems to have a high capacity for adaptation or acclimation to hypoxia (Mandic et al., 2009a, b; Speers-Roesch et al., 2013). Specifically, the two main questions in this study were: 1) Is bullhead more physiologically tolerant to hypoxia (i.e. has a lower $\mathrm{P}_{\text {crit }}$ ) than stone loach?; and 2) Do bullhead and stone loach differ in their hypoxia avoidance behaviour? The results here provide insight into the role of physiological traits in the spread of freshwater invasive species and particularly their ability to tolerate adverse environmental conditions.

\section{Methods and Materials}

\section{Animals and holding conditions}

Fish were collected by electrofishing from the White Cart Water in Pollok Country Park, Glasgow, Scotland (Lat. 55²'25'” N, Long. 4³0’06”' W). Daytime DO levels at the sampling site range from 79 to $106 \%$ air saturation. Night-time DO levels are suspected to drop below this range, particularly during periods of summer eutrophication. Bullhead and stone loach co-exist at this location. Immediately after fish were caught, they were transported by road to Institute of Biodiversity, Animal Health and Comparative Medicine (IBAHCM) in Glasgow, Scotland, United Kingdom. After arrival, bullhead and stone loach were separated and kept in different holding tanks of each (92 litres, Length $(\mathrm{L})=620 \mathrm{~mm}$, Width $(\mathrm{W})=620$ $\mathrm{mm}$ and Depth $(\mathrm{D})=240 \mathrm{~mm})$. Tanks received a dechlorinated freshwater from a recirculating system equipped with mechanical and biological filtration as well as UVsterilisers. Water temperature in each tank was maintained at $14^{\circ} \mathrm{C}\left( \pm 0.5^{\circ} \mathrm{C}\right)$ and the photoperiod in the aquarium was set to a 12:12 light:dark cycle. Fish were fed daily ad libitum with frozen bloodworms and once a week with chunks of small fish. Three months before experiments, all fish (45 stone loaches and 42 bullheads) were lightly anaesthetised using benzocaine and marked for identification using coloured VIE elastomer tags (Northwest Marine Technology Inc.). The fish were then allocated to 5 stone loaches per tank (47 litres, $\mathrm{L}$ $=520 \mathrm{~mm}, \mathrm{~W}=380 \mathrm{~mm}$ and $\mathrm{D}=240 \mathrm{~mm})$ and 6 bullheads per tank $(47$ litres, $\mathrm{L}=520 \mathrm{~mm}$, 
$128 \mathrm{~W}=380 \mathrm{~mm}$ and $\mathrm{D}=240 \mathrm{~mm}$ or $30 \mathrm{~L}, \mathrm{~L}=380 \mathrm{~mm}, \mathrm{~W}=380 \mathrm{~mm}$ and $\mathrm{D}=210 \mathrm{~mm})$. Each of 129 the holding tanks contained gravel substrate, plastic plants and circular plastic pipes to 130 provide shelter. All experiments conducted during this study were in compliance with Home 131 Office legalisation (Project Licence number: 60/4461) in the United Kingdom.

\section{Respirometry assays}

133 Oxygen uptake rate ( $\mathrm{MO}_{2}$, oxygen uptake measurements) of fish was measured using an 134 intermittent-flow respirometry system (Steffensen, 1989; Clark et al., 2013). One glass 135 chamber (163 ml total volume) was submerged in a black 93 litres tank of air-saturated water.

136 Temperature within the experimental tank was controlled by a thermostatic reservoir 137 connected to the experimental tank by a thermoregulator (TMP-REG system, Loligo Systems, 138 Tjele, Denmark) and maintained constant at $14^{\circ} \mathrm{C}\left( \pm 0.2^{\circ} \mathrm{C}\right)$ during the whole measurement period. A continuous mixing circuit $(100 \mathrm{ml} / \mathrm{min})$ was powered by a peristaltic pump

140 (Masterflex L/S 100 RPM, Cole-Parmer, Vernon Hills, US). A UV filter-steriliser minimised

141 bacterial respiration during trials. Oxygen concentration in the chamber was measured every

142 two seconds using a Firesting 4 channel oxygen meter (PyroScience GmbH, Aachen,

143 Germany). A flush pump connected to an automated digital timer (MFRT-1, Superpro

144 Hydroponics) flushed the respirometry chamber for 3 min every 10 min, using oxygenated

145 water from the experimental tank. During the $10 \mathrm{~min}$ off cycle, oxygen uptake rate $\left(\mathrm{MO}_{2}\right)$ was

146 measured by the decline in oxygen concentration in the respirometry chamber. To control the

147 dissolved oxygen (DO) concentration in the water, a galvanic oxygen probe (MINI-DO

148 galvanic cell $\mathrm{O}_{2}$ probe, Loligo Systems, Tjele, Denmark) was submerged within the water

149 bath and attached to an Eheim pump maintaining a constant water flow over the probe

150 membrane. The oxygen probe was connected to an oxymeter unit (OXY-REG, Loligo

151 Systems, Tjele, Denmark) preset to maintain the desired level of oxygen in the water bath.

152 The oxymeter controlled a solenoid valve connected to a tank of gaseous nitrogen. If DO in 153 the experimental tank went above the preset levels on the oxymeter unit $(+1 \%)$, the solenoid 154 valve allowed nitrogen to bubble into a reservoir connected to the tank with the respirometry 155 chamber until preset DO was reached. All $\mathrm{MO}_{2}$ data were recorded as text files obtained from 156 the Firesting $\mathrm{O}_{2}$ software and analysed in LabChart 7 Pro (ADInstuments Pty Ltd, Bella Vista, $157 \mathrm{NSM}$, Australia). $\mathrm{MO}_{2}\left(\mathrm{mg} \mathrm{O}_{2} \mathrm{~h}^{-1}\right)$ data were corrected for the volume of respirometry 158 chamber and tubing in the closed system. 
159 Ten stone loaches (mean \pm s.e.m, $7.16 \pm 0.62 \mathrm{~g}, 9.39 \pm 0.27 \mathrm{~cm}$ ) and ten bullheads (mean \pm 160 s.e.m, $10.99 \pm 0.60 \mathrm{~g}, 8.33 \pm 0.11 \mathrm{~cm}$ ) were randomly selected from their holding tanks and 161 tested individually under normoxic and hypoxic conditions to obtain oxygen uptake rates $162\left(\mathrm{MO}_{2}\right)$. Before experiments, all fish were food-deprived for $48 \mathrm{~h}$. Fish were transferred 163 individually to a circular tank $(\mathrm{D}=50 \mathrm{~cm})$ with a water depth of $10 \mathrm{~cm}$ and manually chased 164 until exhaustion (Killen et al., 2012a; Clark et al., 2013; Killen et al., 2015). Immediately after 165 exhaustion (2-3 min of chasing), fish were placed individually in a respirometry chamber. The 166 manual chase protocol was chosen as both of these fish species are benthic and incapable of 167 performing sustained swimming. The first slope after exercise was divided into $2 \mathrm{~min}$ 168 intervals, with the steepest slope interval being used to calculate the MMR (in $\mathrm{mg} \mathrm{O}_{2} \mathrm{~h}^{-1}$ ) for 169 each fish. Standard metabolic rate (SMR, in $\mathrm{mg} \mathrm{O}_{2} \mathrm{~h}^{-1}$ ) was calculated by taking the lowest $17010 \%$ percentile of values during the whole measurement period (Dupont-Prinet et al., 2010; 171 Killen et al., 2012a; Killen, 2014), excluding the first $5 \mathrm{~h}$ of measurements in the chamber 172 (Killen, 2014). Aerobic scope (AAS, in $\mathrm{mg} \mathrm{O}_{2} \mathrm{~h}^{-1}$ ) was calculated as the absolute difference 173 between MMR and SMR; factorial aerobic scope (FAS) was calculated as the ratio MMR/SMR. MMR was only measured under normoxic conditions. To account for bacterial respiration during the trials, background consumption was measured before and after each trial in the respirometry chamber. $\mathrm{MO}_{2}$ data were corrected as well for background bacterial respiration by assuming a linear increase in background respiration over time.

The next day, measurements of $\mathrm{MO}_{2}$ during exposure to hypoxia were performed starting at $180100 \%$ and followed by progressively lowering DO to 80, 60, 40, 30 and $25 \%$ air saturation at a rate of $20 \% \mathrm{~h}^{-1} . M O_{2}$ measurements were made at each DO level over $1 \mathrm{~h} 20 \mathrm{~min}$ to obtain 6 slopes of oxygen uptake. At $25 \%$ DO, both species showed increased activity indicative of stress of agitation, and so this was the final DO level used for both species. Following the

184 final exposure to $25 \% \mathrm{DO}$, fish was removed from the chamber and transferred to its initial 185 holding tank. DO in the experimental tank was restored to 100\% DO and blank bacterial 186 background respiration was recorded.

\section{Behavioural assays}

189 Behavioural assays were performed on different bullhead and stone loach than those used during respirometry measurements. Behavioural responses of 11 bullheads (mean \pm s.e.m,

$19112.27 \pm 0.90 \mathrm{~g}, 8.81 \pm 0.20 \mathrm{~cm}$ ) and 12 stone loaches (mean \pm s.e.m, $6.49 \pm 0.40 \mathrm{~g}, 9.48 \pm$ 
$0.20 \mathrm{~cm}$ ) to progressive hypoxia were performed in an acrylic arena with circular chambers on

193 either side (each $30 \mathrm{~cm}$ diameter) connected by a small channel $(\mathrm{L}=7 \mathrm{~cm}$ and $\mathrm{W}=5.5 \mathrm{~cm})$.

194 Temperature on each side of the system was controlled and maintained at $14^{\circ} \mathrm{C}$. During

195 hypoxia trials, only one side of the arena was oxygen-depleted to the desired DO level (80,

$19660,40,30,25$ and $20 \%$ air saturation), whereas the other side was constantly maintained at

$197100 \%$ air saturation and served as a potential normoxic refuge. Fish could freely choose

198 between staying under normoxic or hypoxic conditions. Over the trials, designation of

199 hypoxic and normoxic chambers were randomised. DO level in the hypoxic side of the arena

200 was controlled using a solenoid valve and oximeter, as previously described, by bubbling

201 nitrogen into a buffer tank connected to the arena. The DO of both sides (hypoxic and

202 normoxic sides) were monitored and recorded continuously during trials by two oxygen

203 sensors linked to a Firesting 4 channel oxygen meter unit (PyroScience GmbH, Aachen,

204 Germany) connected to a laptop computer. A shelter $(\mathrm{L}=99 \mathrm{~mm}, \mathrm{~W}=50 \mathrm{~mm}, \mathrm{H}=25 \mathrm{~mm})$

205 was provided on the hypoxic side of the tank to encourage fish to stay under hypoxic

206 conditions and to permit observation of a potential trade-off between hypoxia tolerance and

207 willingness to take risk. The shelter was positioned between the inflow and outflow channels

208 ( $\sim 1.5 \mathrm{~cm}$ away from the arena walls). A webcam was mounted above the arena to record the

209 behavioural responses of fish to progressive hypoxia. After $48 \mathrm{~h}$ without food, an individual

210 fish was placed in the arena at 17:00 with a water depth of $7 \mathrm{~cm}$ and left undisturbed

211 overnight in the behavioural arena. During this acclimation time, both sides of the system

212 were set at $100 \%$ DO and maintained at $14^{\circ} \mathrm{C}$. The next day at $\sim 10: 00$, behavioural trials

213 started at $100 \%$ DO to obtain the baseline behaviour of fish at normoxia. DO within the

214 hypoxic side of the arena was then decreased at a rate of $20 \% 15 \mathrm{~min}^{-1}$. At each DO level,

215 behaviour was recorded for $30 \mathrm{~min}$. At the end of each trial individual fish were taken out of

216 the behavioural arena, measured for body mass and length, and returned to the holding tank.

217 The arena was cleaned and filled with clean water and a new individual fish was introduced to

218 the arena to acclimate overnight.

\section{Data and statistical analysis}

\section{Respirometry data}

222 Differences in metabolic traits (MMR, SMR and AAS, FAS) at normoxia between bullhead 223 and stone loach were examined using general linear models (GLMs,) with mass of fish as a 224 continuous covariate and fish species as a categorical variable. Model assumptions were 
verified by visual inspections of residuals versus plots and q-q plots. MMR, SMR and AAS (in $\mathrm{mg} \mathrm{O}_{2} \mathrm{~h}^{-1}$ ) and mass were log-transformed in the models. At each hypoxic DO level during respirometry trials $\left(80,60,40,30\right.$ and $25 \%$ air saturation) the mean value of $M O_{2}$ data for 6 slopes were calculated and used for analyses. To determine $P_{\text {crit }}$ in bullhead $(n=10)$ and in stone loach $(\mathrm{n}=10)$, linear mixed effects models (LME) were used with $\mathrm{MO}_{2}\left(\mathrm{mg} \mathrm{O}_{2} \mathrm{~h}^{-1}\right)$ as the response variable, DO level as a categorical variable (with 6 levels), body mass (g) as a continuous covariate and fish identity as a random effect. $M O_{2}$ and body mass were logtransformed in models. $\mathrm{MO}_{2}$ at normoxia was considered as the reference level in the model. Any DO levels for which $M O_{2}$ was significantly lower than SMR (at $100 \%$ DO) were used to determine $\mathrm{P}_{\text {crit. }}$ A linear regression was plotted through these $\mathrm{MO}_{2}$ data points with a forced yintercept of zero; the resulting linear equation $(y=\beta x$, where $\beta$ is the slope of linear regression and $\mathrm{y}$ is $\mathrm{SMR}$ at $100 \% \mathrm{DO}$, $\mathrm{x}$ represents the estimated $\mathrm{P}_{\text {crit }}$ from the regression and was calculated for bullhead or stone loach separately as followed $\left(\mathrm{P}_{\text {crit }}=\mathrm{y} / \beta\right.$, in \% air saturation of oxygen in freshwater at $\left.14^{\circ} \mathrm{C}\right)$ (Cook \& Herbert, 2012a).

\section{Behavioural data}

Behaviours were quantified from videos with Solomon Coder software (v.14.10.04; Budapest, Hungary). To monitor and identify behavioural avoidance of hypoxia, residence times in the hypoxic and normoxic sides (s), and time spent within the shelter (s) in the hypoxic side were recorded. Residence time in hypoxic and normoxic sides and time spent under shelter on the hypoxic side were calculated as a percentage of total time over the whole $30 \mathrm{~min}$ trial for each DO levels. The effect of DO on behaviour was analysed using GLMs with DO as a categorical variable and different behavioural avoidance measurements as response variables which were tested separately. GLMs were followed with a Tukey HSD posthoc multiple comparison test among DO levels. Differences in behaviour between bullhead and stone loach were tested by performing a Welch two sample $t$ test at each DO level.

Statistical analyses were performed in RStudio (version 3.3.0 The R Foundation for Statistical Computing Platform) with a significance level of $\mathrm{p}<0.05$ using the lmerTest package (Kuznetsova et al., 2015) and MuMIn package (Bartoń, 2015) for calculating $R^{2}$ values of LME models; marginal $R^{2}$ indicates the variance explained by fixed factors, and conditional $R^{2}$ is the corresponding value for when including both fixed and random factors (Nakagawa \& Schielzeth, 2013). Data represented in figures as mean values \pm s.e.m otherwise stated. 


\section{Results}

\section{Respirometry assays}

260 No significant differences for MMR, AAS, or FAS were found between stone loach and bullhead under normoxic conditions at $14^{\circ} \mathrm{C}$ (Figure 1). However, bullhead had a ca. $6.2 \%$ lower normoxic SMR (GLM, effect species, $F_{1,19}=12.75, p=0.002$, Figure 1).

For bullhead, $\mathrm{MO}_{2}$ dropped below SMR at 40\% DO (Figure 2A; Table 1) and then remained below SMR onward during progressive hypoxia. This translated to a $14.52 \%$ decline in $\mathrm{MO}_{2}$ at $40 \%$ DO, a $37.08 \%$ drop at $30 \%$ DO, and $52.86 \%$ drop at $25 \%$ DO. The LME explained $78.69 \%$ of variation observed in changes in metabolic responses to hypoxia in bullhead; $65.38 \%$ of the total variation was explained by DO and body mass, and the remaining $13.31 \%$ of the explained variation was due to individual differences. The estimated $\mathrm{P}_{\text {crit }}$ in bullhead was $4.96 \mathrm{mg} \mathrm{O}_{2} \mathrm{l}^{-1}$ at $14^{\circ} \mathrm{C}$ (Figure $2 \mathrm{~A}$ ).

For stone loach, only $\mathrm{MO}_{2}$ values at $25 \%$ DO were significantly lower than SMR values at $100 \%$ DO (23.68\% lower than SMR; Table 1). Because there was only one DO level at which $\mathrm{MO}_{2}$ for stone loach was below SMR, no precise $\mathrm{P}_{\text {crit }}$ value could be estimated using linear regression in this species (Figure 2B). However, given that $\mathrm{MO}_{2}$ values did not begin to drop below SMR until approximately $40 \% \mathrm{DO}, \mathrm{P}_{\text {crit }}$ for stone loach is likely close to, or lower than, the DO content at this value $\left(4.12 \mathrm{mg} \mathrm{l}^{-1}\right)$. The LME for stone loach explained $80.44 \%$ of the observed variation: $55.91 \%$ was explained by DO and body mass, and the remaining $24.53 \%$ was attributed to individual differences in sensitivity to hypoxia.

\section{Behavioural assays}

282 All bullhead remained in hypoxia for $100 \%$ of time at each DO level tested; with $91.5-100 \%$ of time being spent within the shelter (Table 2). Stone loach similarly preferred to stay in hypoxic conditions over most trials (93.9 - 99.7\% of the time); with $77.5-98.6 \%$ of total trial time being spent in the shelter. In both bullhead and stone loach, hypoxia had no effect on either time spent in the hypoxia side of the arena or the time spent in shelter. No differences in residence time under hypoxia between bullhead and stone loach were observed at most DO

288 levels tested except at $20 \%$ air saturation (Welch two sample $\mathrm{t}$ test; $\mathrm{t}=2.46, \mathrm{df}=11, \mathrm{p}=0.03$ ) where stone loach spent slightly less time in hypoxic conditions ( $96.25 \%$ of time) compared 
to bullhead. No differences were found for time spent under the shelter in hypoxic side

291 between bullhead and stone loach at any DO level tested.

\section{Discussion}

Contrary to expectations, invasive bullhead displayed a relatively low hypoxia tolerance as compared to native stone loach. Although invasive species are believed to have a wide physiological tolerance towards environmental stressors, the results here suggest that bullhead may not be able to exploit hypoxic episodes as a mean to outcompete stone loach by colonising, establishing populations, and expanding their distribution range in novel freshwater habitats. Even though no precise $\mathrm{P}_{\text {crit }}$ value was established for stone loach, the data suggest that stone loach's $\mathrm{P}_{\text {crit }}$ must be lower than that for bullhead. At $25 \% \mathrm{DO}, \mathrm{MO}_{2}$ in bullhead dropped by approximately $50 \%$ of their SMR, nearly double the decline in $\mathrm{MO}_{2}$ observed in stone loach at the same level of oxygen availability. Bullhead belong to sculpin order that are mainly found in marine habitats and known to be moderate to highly hypoxia tolerant (Mandic et al., 2009a, b; Speers-Roesch et al., 2013). However, Mandic and colleagues' studies (2009a, b) found that a freshwater sculpin species (Cottus asper) had one of the higher $\mathrm{P}_{\text {crit }}$ values within this order and therefore was less tolerant to hypoxic conditions compared to marine tide pool sculpins. These findings would suggest that freshwater sculpins may be less hypoxia tolerant as compared to marine sculpins. This could explain why bullhead appeared to have a higher $\mathrm{P}_{\text {crit }}$ compared to marine sculpins found in previous studies.

Interestingly, some freshwater loach species have been observed to have some degree of tolerance to hypoxia. Eggs and larvae of spined loach (Cobitis taenia) can survive under acute exposure to oxygen concentrations (2.1-2.2 $\mathrm{mg} \mathrm{O}_{2} \mathrm{l}^{-1}$ at $21^{\circ} \mathrm{C}$; Bohlen, 2003). Stone loach in particular are capable of respiring through their intestines after ingesting air (Maitland, 2007). As we did not conduct bimodal respirometry trials (Lefevre et al., 2011, 2015), we were unable to determine the proportion of aerial respiration utilised during normoxic and hypoxic conditions in stone loach. However, stone loach were denied access to aerial oxygen before and during measurements of $\mathrm{P}_{\text {crit }}$ (approx. $36 \mathrm{~h}$ without access to air), and so it is unlikely that they utilised a secondary method of oxygen uptake during this time. Still, even without this potential means of increasing oxygen uptake, stone loach displayed an increased physiological capacity for tolerating hypoxia as compared to bullhead. 
The current study was conducted at $14^{\circ} \mathrm{C}$, near the lower range of summer temperatures at which stone loach and bullhead would be subjected to. Due to increases in metabolic demand, $\mathrm{P}_{\text {crit }}$ may increase at higher temperatures. If the reaction norms for $\mathrm{P}_{\text {crit }}$ in response to temperature vary between stone loach and bullhead, it is conceivable that the relative hypoxia tolerance of these two species could change at higher temperatures. This sort of interaction between temperature and hypoxia tolerance would be a possibility for future research. However, given that the upper thermal limit $\left(\mathrm{CT}_{\max }\right)$ for bullhead $\left(27.6^{\circ} \mathrm{C}\right)$ is lower than that of stone loach $\left(29.1^{\circ} \mathrm{C}\right)$ (Elliott et al., 1994, 1995), it is likely that bullhead may be even less hypoxia tolerant as stone loach at higher temperatures.

No difference in avoidance behaviour towards hypoxic conditions was found between

334 bullhead and stone loach except at the lowest DO level tested (20\% air saturation) where stone loach spent moderately less time under hypoxic conditions (96.25\% of time) compared to bullhead which spent $100 \%$ of the time under hypoxia conditions across trials. Stone loach displayed short and abrupt excursions away from the shelter and into normoxic side of the behavioural arena with highest time spent in normoxia at 25\% DO level. Stone loach showed similar behavioural responses towards progressive hypoxia as bullhead did, even though stone loach tend to be more active and may have higher routine energy requirements than bullhead (Nati unpublished). The short explorative excursions into normoxia performed by stone loach may have been performed to quickly restore and maintain their potentially higher routine metabolic oxygen demands. Despite these trips into normoxia, no statistically significant differences in behaviour compared to baseline behaviour under normoxic conditions could be found for stone loach, either on time spent in hypoxia or time spent under shelter. Bullhead showed no avoidance behaviour toward progressive hypoxia and mostly stayed hiding under the provided shelter. Avoidance responses in fish to hypoxia vary according to the nature of hypoxic episode (exposure time, localised or generalised), lifestyle (migratory or sedentary), locomotor ability and opportunity of escaping to more favourable habitats (Chapman \& McKenzie, 2009). Benthic fish species as bullhead and stone loach have very little swimming capacity and might use different behavioural strategies towards progressive hypoxia events. Exploring and finding more favourable environments can be energetically costly. Additionally, these novel habitats might be less suitable in terms of food and cover availability and have higher predation risk than the hypoxic habitats. For these reasons, some species may choose to stay in hypoxic zones, particularly if they are accustomed to relatively 
are known to be especially poor swimmers (Tudorache et al., 2008) and are very territorial (Smyly, 1957). Due to these characteristics, it might be energetically disadvantageous and highly costly for bullhead to invest energy into exploration and active strategies for avoiding hypoxic zones and potentially abandoning their established territories.

A number of other factors besides hypoxia tolerance may affect competitive interactions between bullhead and stone loach. While stone loach and bullhead can compete for resources such as food and shelter, they are sometimes able to co-exist through habitat partitioning (Welton et al., 1983, 1991). However, the degree of co-existence appears to be linked to population density of each species. In rivers where bullhead are highly abundant, stone loach are rarely found (Yeomans W. pers. obs.), possibly due to limited shelter availability and increased predation by birds. In addition, stone loach appear to have higher levels of spontaneous activity (Nati unpublished). This would not only make them more visible to predators but it would also increase routine energy requirements and likely make them generally more reliant on aerobic metabolism. Bullhead, on the other hand, may rely more on anaerobic pathways (Mandic et al., 2013) to fuel metabolism and survive under harsh conditions, particularly in hypoxic events. In this study, we did not investigate differences in anaerobic metabolic capacity between these two species, but this would be a promising area for future research. Differences in diet preference or tolerance to periods of reduced food availability could also affect competiveness in areas where bullhead and stone loach overlap (Killen et al., 2016).

The current study suggests that invasive bullhead have a reduced hypoxia tolerance as compared to native stone loach. Although differences in hypoxia tolerance do not seem to have facilitated the spread of the invasive species in this case, there may be other scenarios where hypoxia has played a key role in the range expansion of invasive aquatic species. Additional research is needed to examine how organ- or tissue-level traits may also explain differences in the physiological tolerance to hypoxia in potential invaders such as differences in hematocrit, oxygen binding capacity of hemoglobin and different levels or isoforms of anaerobic enzymes in relevant tissues (e.g. brain, liver) to understand why certain invaders may be able to thrive in hypoxia. Overall, more investigation is required into different native versus invasive species pairs, looking into tolerance ranges toward different environmental stressors, integrating physiology and behaviour over different environmental contexts. 
392

393

394

395

396

397

398

399

400

401

402

403

404

405

406

407

408

409

410

411

412

413

414

415

416

417

418

419

420

421

422

423

424

425

426

427

428

429

JJHN was supported by an Aides à la Formation Recherche doctoral grant from the Fonds National de la Recherche Luxembourg (4005263). SSK was supported by NERC Advanced Fellowship NE/J019100/1 and European Research Council Starting Grant 640004. We would like to thank IBAHCM Graham Kerr technical staff, Graham Law, Graham Anderson, Graham Adam, Pat McLaughlin, Ross Phillips, Alastair Kirk for their technical support during this study. We would like to acknowledge and thank the Clyde River Foundation staff, David McColl and Lesley Deans for helping to collect fish used during this study. We also thank two anonymous reviewers for their feedback on an earlier version of this manuscript.

\section{Conflict of Interest Statement}

The authors declare no competing interests

\section{References}

Anderson, H., Futter, M., Oliver, I., Redshaw, J., \& Harper, A. (2010). Trends in Scottish river water quality. Bartoń, K. (2015). MuMIn: Multi-Model Inference. In R package version 1.15.1.

Blanchet, S., Loot, G., Grenouillet, G. \& Brosse, S. (2007). Competitive interactions between native and exotic salmonids: a combined field and laboratory demonstration. Ecology of Freshwater Fish, 16, 133-143.

Bohlen, J. (2003). Temperature and oxygen requirements of early life stages of the endangered spined loach, Cobitis taenia L. (Teleostei, Cobitidae) with implications for the management of natural populations. Archiv für Hydrobiologie, 157, 195-212.

Brady, D. C., Targett, T. E., \& Tuzzolino, D. M. (2009). Behavioral responses of juvenile weakfish (Cynoscion regalis) to diel-cycling hypoxia: swimming speed, angular correlation, expected displacement, and effects of hypoxia acclimation. Canadian Journal of Fisheries and Aquatic Sciences, 66, 415-424. Chapman, L. J., \& McKenzie, D. J. (2009). Behavioural responses and ecological consequences. In Fish Physiology, Vol. 27 (ed. J. G. Richards, A. P. Farrell and C. J. Brauner), pp. 25-77. San Diego, Elsevier.

Clark, T. D., Sandblom, E., \& Jutfelt, F. (2013). Aerobic scope measurements of fishes in an era of climate change: respirometry, relevance and recommendations. The Journal of Experimental Biology, 216, 2771-2782. doi:10.1242/jeb.084251.

Cook, D. G., \& Herbert, N. A. (2012)a. Low O2 avoidance is associated with physiological perturbation but not exhaustion in the snapper (Pagrus auratus: Sparidae). Comparative Biochemistry and Physiology. Part A, Molecular \& Integrative Physiology, 162, 310-316. doi:10.1016/j.cbpa.2012.03.024.

Cook, D. G., \& Herbert, N. A. (2012)b. The physiological and behavioural response of juvenile kingfish (Seriola lalandi) differs between escapable and inescapable progressive hypoxia. Journal of Experimental Marine Biology and Ecology, 413, 138-144. doi:10.1016/j.jembe.2011.12.006. 
Costedoat, C., Pech, N., Chappaz, R., Salducci, M. D., Lim, P. \& Gilles, A. (2004). Study of introgressive hybridization between Chondrostoma t. toxostoma and Chondrostoma n. nasus (Teleostei, Cyprinidae) using multiple approaches. Cybium, 28, 51-61.

D’Amato, M. E., Esterhuyse, M. M., van derWaal, B. C. W., Brink, D. \& Volckaert, F. A. M. (2007). Hybridization and phylogeography of the Mozambique tilapia Oreochromis mossambicus in southern Africa evidenced by mitochondrial and microsatellite DNA genotyping. Conservation Genetics, 8, 475-488.

Diaz, R. J. (2001). Overview of hypoxia around the world. Journal of Environmental Quality, 30(2), 275-281.

Diaz, R. J., \& Rosenberg, R. (2008). Spreading dead zones and consequences for marine ecosystems. Science, 321, 926-929. doi:10.1126/science.1156401.

Domenici, P., Steffensen, J. F., \& Batty, R. S. (2000). The effect of progressive hypoxia on swimming activity and schooling in Atlantic herring. Journal of Fish Biology, 57, 1526-1538. doi:10.1006/jfbi.2000.1413.

Domenici, P., Lefrançois, C., \& Shingles, A. (2007). Hypoxia and the antipredator behaviours of fishes. Philosophical transactions of the Royal Society of London. Series B, Biological sciences, 362, 2105-2121. doi:10.1098/rstb.2007.2103.

Dupont-Prinet, A., Chatain, B., Grima, L., Vandeputte, M., Claireaux, G., \& McKenzie, D. J. (2010). Physiological mechanisms underlying a trade-off between growth rate and tolerance of feed deprivation in the European sea bass (Dicentrarchus labrax). Journal of Experimental Biology, 113, 1143-1152.

Elliott, J. M., Elliott, J. A. \& Allonby, J. D. (1994). The critical thermal limits for the stone loach, Noemacheilus harhatulus, from three populations in north-west England. Freshwater Biology, 32, 593-601.

Elliott, J. M. \& Elliott, J. A. (1995). The critical thermal limits for the bullhead, Cottus gobio, from three populations in north- west England. Freshwater Biology, 33, 411-419. doi:10.1111/j.1365-2427.1994.tb01150.x.

Elshout, P. M. F., Dionisio Pires, L. M., Leuven, R. S. E. W., Wendelaar Bonga, S. E., \& Hendriks, A. J. (2013). Low oxygen tolerance of different life stages of temperate freshwater fish species. Journal of Fish Biology, 83, 190-206. doi:10.1111/jfb.12167.

Ficke, A. D., Myrick, C. A., \& Hansen, L. J. (2007). Potential impacts of global climate change on freshwater fisheries. Reviews in Fish Biology and Fisheries, 17, 581-613.

Graham, C. T., \& Harrod, C. (2009). Implications of climate change for the fishes of the British Isles. Journal of Fish Biology, 74, 1143-1205.

Gozlan, R. E., St-Hilaire, S., Feist, S. W., Martin, P. \& Kent, M.L. (2005). Biodiversity disease threat to European fish. Nature, 435, 1046.

Gozlan, R. E., Peeler, E. J., Longshaw, M., St-Hilaire, S. \& Feist, S. W. (2006). Effect of microbial pathogens on the diversity of aquatic populations, notably in Europe. Microbes and Infection, 8, 1358-1364. doi:10.1016/j.micinf.2005.12.010.

Gozlan, R. E. (2008). Introduction of non-native freshwater fish: is it all bad? Fish and Fisheries, 9, 106-115.

Herbert, N. A., \& Steffensen, J. F. (2005). The response of Atlantic cod, Gadus morhua, to progressive hypoxia: fish swimming speed and physiological stress. Marine Biology, 147, 1403-1412. doi:10.1007/s00227-005-0003-8. Jewett, E. B., Hines, A. H., \& Ruiz, G. M., (2005). Epifaunal disturbance by periodic low levels of dissolved oxygen: native vs. invasive species response. Marine Ecology Progress Series, 304, 31-44.

Killen, S. S., Marras, S., Steffensen, J. F., \& McKenzie, D. J. (2012a). Aerobic capacity influences the spatial position of individuals within fish schools. Proceedings of the Royal Society B: Biological Sciences, 279, 357-364. 
Killen, S. S., Marras, S., Ryan, M. R., Domenici, P., \& McKenzie, D. J. (2012b). A relationship between metabolic rate and risk-taking behaviour is revealed during hypoxia in juvenile European sea bass. Functional Ecology, 26, 134-143. doi:10.1111/j.13652435.2011.01920.x.

Killen, S. S. (2014). Growth Trajectory Influences Temperature Preference in Fish Through an Effect on Metabolic Rate. The Journal of Animal Ecology, 83, 1-10.

Killen, S. S., Nati, J. J. H., \& Suski, C. D. (2015). Vulnerability of individual fish to capture by trawling is influenced by capacity for anaerobic metabolism. Proceedings Biological Sciences / The Royal Society, 282, 1-7. doi:10.1098/rspb.2015.0603. Killen, S. S., Glazier, D., Rezende, E. L., Clark, T., Atkinson, D., Willener, A. \& Halsey, L. G. (2016). Ecological influences and physiological correlates of metabolic rates in teleost fishes. The American Naturalist, 187, 592-606. doi: 10.1086/685893.

Kitchell, J. F., Schindler, D. E., Ogutu-Ohwayo, R. \& Reinthal, P. N. (1997). The Nile perch in Lake Victoria: interactions between predation and fisheries. Ecological Applications, 7 , 653-664.

Kolar, C. S., \& Lodge, D. M. (2002). Ecological predictions and risk assessment for alien fishes in North America. Science, 298, 1233-1236. doi:10.1126/science.1075753.Kuznetsova A., Brockhoff P. B., \& Bojesen R. H. (2016). Package "lmerTest" in R. Tests in Linear Mixed Effects Models.

Landman, M. J., Van Den Heuvel, M. R., \& Ling, N. (2005). Relative sensitivities of common freshwater fish and invertebrates to acute hypoxia. New Zealand Journal of Marine and Freshwater Research, 39, 1061-1067. doi:10.1080/00288330.2005.9517375.

Lefevre, S., Huong D. T. T., Wang T., Phuong, N. T., \& Bayley M. (2011). Hypoxia tolerance and partitioning of bimodal respiration in the striped catfish (Pangasianodon hypophthalmus). Comparative Biochemistry and Physiology - A Molecular and Integrative Physiology, 158(2), 207-214.

Lefevre, S., Bayley, M., \& McKenzie, D. J. (2015). Measuring oxygen uptake in fishes with bimodal respiration. Journal of Fish Biology, 1, 1-26.

Lenz, M., da Gama, B. A. P., Gerner, N. V., Gobin, J., Gröner, F., Harry, A. et al. (2011). Non-native marine invertebrates are more tolerant towards environmental stress than taxonomically related native species: results from a globally replicated study. Environmental Research, 111, 943-952. doi:10.1016/j.envres.2011.05.001.

Maitland, P. S., \& Campbell, R. N. (1992). Freshwater fishes. Glasgow, Harper Collins, pp.369.

Maitland, P. S. (2007). Scotland's Freshwater Fish: Ecology, Conservation \& Folklore. Trafford Publishing.

Mandic, M., Sloman, K. A., \& Richards, J. G. (2009)a. Escaping to the surface: a phylogenetically independent analysis of hypoxia-induced respiratory behaviors in sculpins. Physiological and Biochemical Zoology, 82, 730-738. DOI:10.1086/605932. Mandic, M., Todgham, A. E., \& Richards, J. G. (2009)b. Mechanisms and evolution of hypoxia tolerance in fish. Proceedings Biological Sciences / The Royal Society, 276, 735-744. doi:10.1098/rspb.2008.1235.

Mandic, M., Speers-Roesch, B., \& Richards, J. G. (2013). Hypoxia tolerance in sculpins is associated with high anaerobic enzyme activity in brain but not in liver or muscle. Physiological and Biochemical Zoology, 86, 92-105. doi:10.1086/667938.

Morosawa, T. (2011). Hypoxia tolerance of three native and three alien species of bitterling inhabiting Lake Kasumigaura, Japan. Environmental Biology of Fishes, 91, 145-153. doi:10.1007/s10641-011-9767-5. 
Moyle P. B. (1986) Fish introductions into North America: patterns and ecological impact. In Ecology of Biological Invasions of North America and Hawaii (ed. H. A. Mooney and J. A.

530 Drake), pp 27-43. New York, Springer-Verlag. Nakagawa, S., \& Schielzeth, H. (2013). A general and simple method for obtaining $\mathrm{R}^{2}$ from generalized linear mixed-effects models. Methods in Ecology and Evolution, 4, 133-142. Poff, N. L., Brinson, M. M., \& Day, J. W. (2002). Aquatic Ecosystems \& Global Climate Change - Potential Impacts on Inland Freshwater and Coastal Wetland Ecosystems in the United States. Arlington, VA: Pew Center on Global Climate Change.

Richards, J. G., Farrell, A. P., \& Brauner, C. J. (2009). Hypoxia. In Fish Physiology, Vol. 27 (ed. A. P. Farrell and C. J. Brauner), pp. 528. San Diego: Academic Press.

Sala, O. E., Chapin, F. S., Armesto, J. J., Berlow, E. \& Bloomfield, J. (2000). Global Biodiversity Scenarios for the Year 2100. Science, 287, 1770-1774. doi:10.1126/science.287.5459.1770.

Schurmann, H., \& Steffensen, J. F. (1997). Effects of temperature, hypoxia and activity on the metabolism of Atlantic cod, Gadus morhua. Journal of Fish Biology, 50, 1166-1180. Shingles, A., McKenzie, D. J., Claireaux, G., \& Domenici, P. (2005). Reflex Cardioventilatory Responses to Hypoxia in the Flathead Gray Mullet (Mugil cephalus) and Their Behavioral Modulation by Perceived Threat of Predation and Water Turbidity. Physiological and Biochemical Zoology, 78, 744-755.

Speers-Roesch, B., Mandic, M., Groom, D. J. E., \& Richards, J. G. (2013). Critical oxygen tensions as predictors of hypoxia tolerance and tissue metabolic responses during hypoxia exposure in fishes. Journal of Experimental Marine Biology and Ecology, 449, 239-249. doi:10.1016/j.jembe.2013.10.006.

Steffensen, J. F. (1989). Some errors in respirometry of aquatic breathers. Fish Physiology and Biochemistry, 6, 49-59.

Smyly, W. J. P. (1957). The life-history of the bullhead or miller's thumb (Cottus gobio L.). Proceedings of Zoological Society of London, 128, 431-453.

Tudorache, C., Viaene, P., Blust, R., Vereecken, H., \& De Boeck, G. (2008). A comparison of swimming capacity and energy use in seven European freshwater fish species. Ecology of Freshwater Fish, 17, 284-291. doi:10.1111/j.1600-0633.2007.00280.x.

Welton, J. S., Mills, C. A. \& Rendle, E. L. (1983). Food and habitat partitioning in two small benthic fishes, Noemacheilus barbatula (L.) and Cottus gobio L. Arch. Hydrobiol., 97, 434454.

Welton, J. S., Mills, C. A. \& Pygott, J. R. (1991). The effect of interaction betweenn the stone loach Noemacheilus barbatula (L.) and the bullhead Cottus gobio (L.) on prey and habitat selection. Hydrobiology, 200, 1-7.

Williamson, M. H. \& Fitter, A. (1996). The characters of successful invaders. Biological Conservation, 78, 163-170. 
Table 1. Results of the linear mixed effects model for oxygen uptake during progressive hypoxia in bullhead ( $\mathrm{n}=$ 10) and stone loach $(\mathrm{n}=10)$. The reference level in the model was $\log \mathrm{SMR}\left(\mathrm{mg} \mathrm{O}_{2} \mathrm{~h}^{-1}\right)$ at normoxia $(100 \%$ air saturation) and $14^{\circ} \mathrm{C}$. Fish ID was included as a random effect in the model.

\begin{tabular}{|c|c|c|c|c|c|c|c|c|c|c|}
\hline \multirow{2}{*}{$\begin{array}{c}\text { Fixed } \\
\text { Effects }\end{array}$} & \multicolumn{5}{|c|}{ Bullhead } & \multicolumn{5}{|c|}{ Stone loach } \\
\hline & estimate & s.e.m & d.f. & $t$ & $p$ & estimate & s.e.m & d.f. & $t$ & $p$ \\
\hline Intercept & -0.545 & 0.322 & 8.09 & 1.691 & 0.129 & -0.764 & 0.183 & 8.21 & -4.182 & 0.003 \\
\hline $80 \%$ & 0.062 & 0.038 & 45 & 1.661 & 0.104 & 0.083 & 0.032 & 45 & 2.600 & 0.013 \\
\hline $60 \%$ & -0.008 & 0.038 & 45 & -0.202 & 0.841 & 0.051 & 0.032 & 45 & 1.604 & 0.116 \\
\hline $40 \%$ & -0.077 & 0.038 & 45 & -2.061 & 0.045 & -0.0003 & 0.032 & 45 & -0.010 & 0.992 \\
\hline $30 \%$ & -0.212 & 0.038 & 45 & -5.634 & $<0.001$ & -0.059 & 0.032 & 45 & -1.860 & 0.069 \\
\hline $25 \%$ & -0.348 & 0.038 & 45 & -9.258 & $<0.001$ & -0.136 & 0.032 & 45 & -4.273 & $<0.001$ \\
\hline $\begin{array}{c}\log \text { mass } \\
(\mathrm{g})\end{array}$ & 0.494 & 0.31 & 8 & 1.595 & 0.149 & 0.762 & 0.214 & 8 & 3.556 & 0.007 \\
\hline \multicolumn{11}{|l|}{$\begin{array}{c}\text { Random } \\
\text { Effect }\end{array}$} \\
\hline \multirow{2}{*}{$\begin{array}{l}\text { Individual } \\
\text { variation }\end{array}$} & & Variance & & Std. Dev & & & Variance & & Std. Dev & \\
\hline & & 0.004 & & 0.066 & & & 0.006 & & 0.080 & \\
\hline Residual & & 0.007 & & 0.083 & & & 0.005 & & 0.071 & \\
\hline
\end{tabular}

581 583

584

585

586

Table 2. Percentage of time spent $( \pm$ s.e.m) in either normoxia or various levels of hypoxia, as well as the time spent in a shelter within the hypoxic zone, for bullhead $(\mathrm{n}=11)$ and stone loach $(\mathrm{n}=12)$ at $14^{\circ} \mathrm{C}$.

\begin{tabular}{ccccccc}
\hline $\begin{array}{c}\text { Oxygen } \\
\text { Availability } \\
\text { (\% air sat.) }\end{array}$ & $\begin{array}{c}\text { Hypoxia } \\
\text { time }\end{array}$ & Shelter time & $\begin{array}{c}\text { Normoxia } \\
\text { time }\end{array}$ & $\begin{array}{c}\text { Hypoxia } \\
\text { time }\end{array}$ & Shelter time & $\begin{array}{c}\text { Normoxia } \\
\text { time }\end{array}$ \\
\hline $100 \%$ & 100 & $91.54 \pm 8.46$ & 0 & $99.73 \pm 0.23$ & $98.61 \pm 1.25$ & $0.27 \pm 0.23$ \\
$80 \%$ & 100 & 100 & 0 & $97.83 \pm 1.83$ & $95.24 \pm 2.47$ & $2.16 \pm 1.83$ \\
$60 \%$ & 100 & 100 & 0 & $99.08 \pm 0.60$ & $96.21 \pm 2.42$ & $0.92 \pm 0.60$ \\
$40 \%$ & 100 & $99.90 \pm 0.10$ & 0 & $97.47 \pm 1.40$ & $93.47 \pm 3.68$ & $2.53 \pm 1.40$ \\
$30 \%$ & 100 & $98.75 \pm 1.25$ & 0 & $96.19 \pm 2.44$ & $87.35 \pm 6.55$ & $3.98 \pm 2.43$ \\
$25 \%$ & 100 & $98.38 \pm 1.27$ & 0 & $93.93 \pm 3.34$ & $81.91 \pm 9.06$ & $6.07 \pm 3.34$ \\
$20 \%$ & 100 & $92.88 \pm 6.73$ & 0 & $96.25 \pm 1.52$ & $77.46 \pm 9.42$ & $3.75 \pm 1.52$ \\
\hline
\end{tabular}



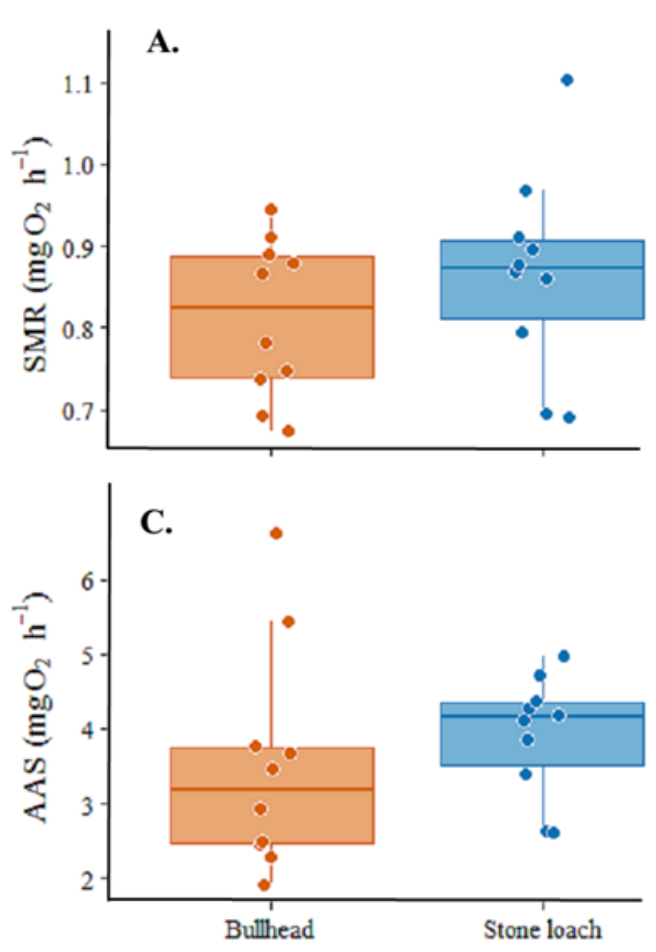
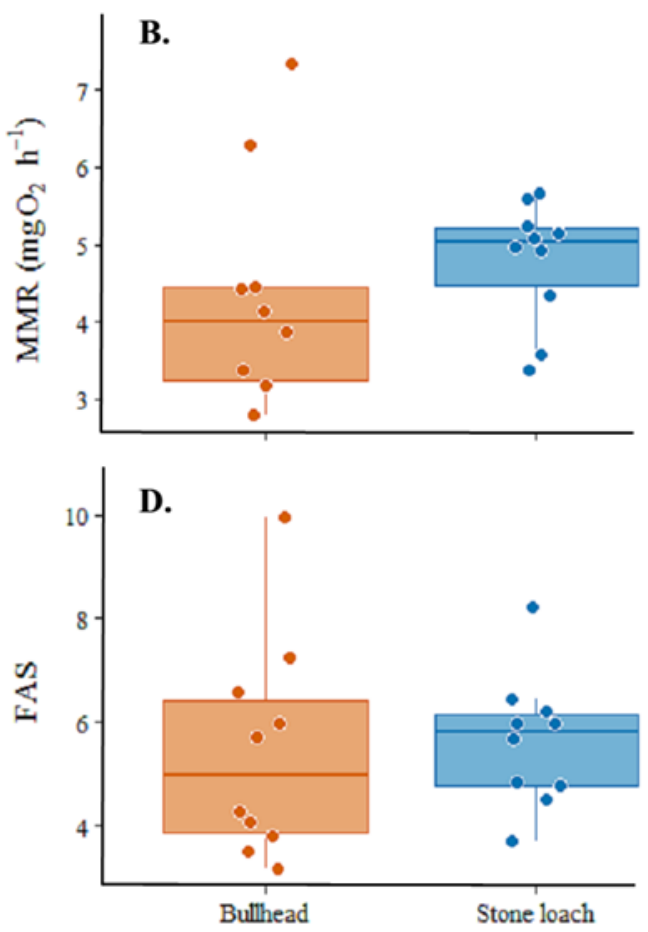

Figure 1. Metabolic traits $\left(\mathrm{mg} \mathrm{O}_{2} \mathrm{~h}^{-1}\right)$ in bullhead (red boxes) and stone loach (blue boxes) adjusted to the mean mass of all fish tested (mass $=9.07 \pm 0.61 \mathrm{~g}$ ) in the respirometry assays.: A) standard metabolic rate, SMR; B) maximum metabolic rate, MMR C) absolute aerobic scope, AAS; D) factorial aerobic scope, FAS at $14^{\circ} \mathrm{C}$. Dots represent individual metabolic traits data.
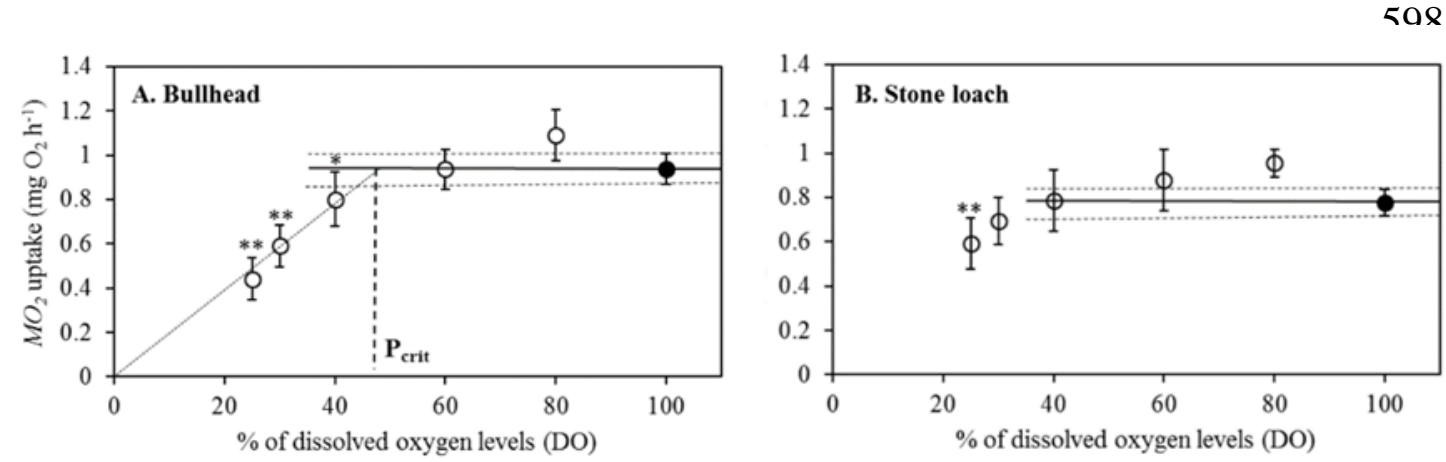

Figure 2. Respiratory responses in bullhead (A.) and stone loach (B.) to progressive hypoxia at different dissolved oxygen levels (DO; 100, 80, 60, 40, 30 and $25 \%$ air saturation) and at $14^{\circ} \mathrm{C}$. The closed circle represents SMR of bullhead $\left(0.938 \pm 0.068 \mathrm{mg} \mathrm{O}_{2} \mathrm{~h}^{-1}\right)$ and stone loach $\left(0.777 \pm 0.061 \mathrm{mg} \mathrm{O}_{2} \mathrm{~h}^{-1}\right)$ under normoxia. The horizontal black lines are SMR extrapolated over the range of DO levels tested with associated 95\% C.I. values (dotted lines). Open circles indicate $\mathrm{MO}_{2}$ during progressive hypoxia. Linear regression (diagonal line) is plotted through $\mathrm{MO}_{2}$ values significantly lower than defined SMR (with asterisks) with a forced intercept $\mathrm{y}=0$. Intercept point between regression line and extrapolated mean value of SMR represents $\mathrm{P}_{\text {crit }}\left(4.96 \mathrm{mg} \mathrm{O}_{2} \mathrm{l}^{-1}\right.$ at $\left.14^{\circ} \mathrm{C}\right)$. For bullhead, metabolic rates were corrected for the mean body size $(10.99 \pm 0.60$ g) using the residuals for regression of log SMR versus log body mass derived equation for SMR $\left(\mathrm{mg} \mathrm{O}_{2} \mathrm{~h}^{-1}\right)=$ $0.4942 *(10.99)-0.642$. For stone loach, metabolic rates were corrected for the mean body size $(7.16 \pm 0.62 \mathrm{~g})$ using the residuals for regression of $\log$ SMR versus log body mass derived equation for SMR $\left(\mathrm{mg} \mathrm{O}_{2} \mathrm{~h}^{-1}\right)=$ $0.7617 *(7.16)-0.7742 . \mathrm{MO}_{2}$ uptake data represented in this figure is not log-transformed. Symbols and error bars are represented as mean $\pm 95 \%$ C.I. with “*” $p<0.05$ and “**” $p<0.001$. 